\title{
Incidence of appropriate cardioverter-defibrillator shocks and mortality in patients with implantable cardioverter- defibrillators with ischemic cardiomyopathy versus nonischemic cardiomyopathy at 33-month follow-up
}

\author{
Kaushang Gandhi ${ }^{1,2}$, Wilbert S. Aronow ${ }^{1,2}$, Harit Desai ${ }^{1,2}$, Harshad Amin ${ }^{1,2}$, Hoang M. Lai ${ }^{1,2}$, \\ William H. Frishman ${ }^{1,2}$, Martin Cohen ${ }^{1,2}$, Carmen Sorbera ${ }^{1,2}$
}

1Department of Medicine, Cardiology Division, New York Medical College, Valhalla, NY,
USA
2Department of Clinical Sciences, University of Texas Southwestern Medical Center,
Dallas, TX, USA

Submitted: 17 July 2009

Accepted: 13 September 2009

Arch Med Sci 2010; 6, 6: 900-903

DOI: 10.5114 /aoms.2010.19299

Copyright (c 2010 Termedia \& Banach

\begin{abstract}
Introduction: The aim of the study was to investigate at long-term follow-up the incidence of appropriate implantable cardioverter-defibrillator (ICD) shocks and of all-cause mortality in patients with ICDs with ischemic cardiomyopathy versus nonischemic cardiomyopathy.

Material and methods: ICDs were implanted in 485 patients with ischemic cardiomyopathy and in 299 patients with nonischemic cardiomyopathy, all of whom had coronary angiography. Baseline characteristics were not significantly different between the 2 groups. Follow-up was 965 days in patients with ischemic cardiomyopathy versus 1039 days in patients with nonischemic cardiomyopathy ( $p$ not significant). The ICDs were interrogated every 3 months to see if shocks occurred.

Results: Appropriate ICD shocks occurred in 179 of 485 patients (37\%) with ischemic cardiomyopathy and in 93 of 299 patients (31\%) with nonischemic cardiomyopathy ( $p$ not significant). All-cause mortality occurred in 162 of 485 patients (33\%) with ischemic cardiomyopathy and in 70 of 299 patients (23\%) with nonischemic cardiomyopathy $(p=0.002)$.

Conclusions: The incidence of appropriate ICD shocks was not significantly different at 33-month follow-up in patients with ischemic cardiomyopathy versus nonischemic cardiomyopathy. However, patients with ischemic cardiomyopathy had a significantly higher incidence of all-cause mortality than patients with nonischemic cardiomyopathy $(p=0.002)$.
\end{abstract}

Key words: ischemic cardiomyopathy, nonischemic cardiomyopathy, cardioverterdefibrillator shocks

\section{Introduction}

Implantable cardioverter-defibrillators (ICDs) have been shown to reduce all-cause mortality in patients with ischemic heart disease [1-5] and in patients with nonischemic cardiomyopathy [5, 6]. At 30-month follow-up of 148 patients with ischemic heart disease and an ICD and of 60 patients with nonischemic heart disease and an ICD, ventricular tachycardia and ventricular fibrillation episodes per month were not significantly different
Corresponding author:

Prof. Wilbert S. Aronow, MD, FACC, FAHA

Department of Medicine Cardiology Division

New York Medical College Macy Pavilion, Room 138 Valhalla, NY 10595, USA Phone: +914 4935311

Fax: +914 2356274

E-mail:wsaronow@aol.com 
between the 2 groups [7]. At 19-month follow-up of 105 patients with ischemic cardiomyopathy and of 48 patients with nonischemic cardiomyopathy and nonsustained ventricular tachycardia, appropriate ICD shocks occurred in $50 \%$ of patients with nonischemic cardiomyopathy versus $36 \%$ of patients with ischemic cardiomyopathy ( $p$ not significant) [8].

The incidence of appropriate ICD shocks and of all-cause mortality at long-term follow-up in a large number of patients with ischemic cardiomyopathy versus nonischemic cardiomyopathy needed to be investigated. The present article reports the incidence of appropriate ICD shocks and of all-cause mortality at 33-month follow-up in 485 patients with ischemic cardiomyopathy and in 299 patients with nonischemic cardiomyopathy.

\section{Material and methods}

There were 485 patients (83\% men and 17\% women), mean age 71 years, with ischemic cardiomyopathy and an ICD and 299 (78\% men and $22 \%$ women), mean age 71 years, with nonischemic cardiomyopathy and an ICD. All 485 patients with ischemic cardiomyopathy had coronary angiographic evidence of obstructive coronary artery disease and a reduced left ventricular ejection fraction. All 299 patients with nonischemic cardiomyopathy had coronary angiographic evidence of no coronary artery disease and a reduced left ventricular ejection fraction.

All 485 patients with ischemic cardiomyopathy and 299 patients with nonischemic cardiomyopathy had an ICD implanted for secondary or primary prevention of sudden cardiac death as a class I indication according to the American College of Cardiology/American Heart Association guidelines for implantation of an ICD in patients with ischemic or nonischemic cardiomyopathy [9]. All patients with ischemic cardiomyopathy had complete revascularization of obstructive coronary artery disease [10] by percutaneous coronary intervention or by coronary artery bypass graft surgery.

At follow-up every 3 months, the ICD was interrogated to see if any shocks occurred. The shocks were further evaluated by an electrophysiologist viewing the intracardiac electrocardiograms to see if they were appropriate. Appropriate ICD shocks were for the treatment of ventricular tachycardia or ventricular fibrillation.

Student's t-tests were used to compare continuous variables between the groups. Chisquare tests and Fisher's exact tests were used to compare dichotomous variables between the groups.

The institutional review boards of Westchester Medical Center and of New York Medical College approved this study.

\section{Results}

Table I shows the baseline characteristics of the patients with ischemic cardiomyopathy and an ICD and of the patients with nonischemic cardiomyopathy and an ICD. No significant differences were present between the 2 groups.

Table II shows at 33-month follow-up the incidence of appropriate ICD shocks and of all-cause mortality in patients with ischemic cardiomyopathy versus nonischemic cardiomyopathy. Table II also shows levels of statistical significance. Sixty-three of 179 ischemic cardiomyopathy patients (35\%) who had appropriate ICD shocks and 31 of 93 nonischemic cardiomyopathy patients (33\%) who had appropriate ICD shocks died (p not significant). Inappropriate ICD shocks occurred in 38 of 485 ischemic cardiomyopathy patients (8\%) and in 21 of 299 nonischemic cardiomyopathy patients (7\%) ( $p$ not significant).

Of the 162 patients with ischemic cardiomyopathy who died, 91 (56\%) died of congestive heart failure, 48 (30\%) died of sudden cardiac death, 11 (7\%) died of fatal myocardial infarction, and 12 (7\%) died of a noncardiac cause. Of the 70 patients with nonischemic cardiomyopathy who died, 42 (60\%) died of congestive heart failure, 22 (31\%) died of sudden cardiac death, $0(0 \%)$ died of fatal myocardial

Table I. Baseline characteristics of patients with implantable cardioverter-defibrillators with ischemic cardiomyopathy vs. nonischemic cardiomyopathy

\begin{tabular}{|lcc|}
\hline Variable & $\begin{array}{c}\text { Ischemic } \\
\text { cardiomyopathy } \\
(n=485)\end{array}$ & $\begin{array}{c}\text { Nonischemic } \\
\text { cardiomyopathy } \\
(n=299)\end{array}$ \\
\hline Age [years] & $71 \pm 11$ & $71 \pm 13$ \\
\hline Men, $n$ (\%) & $402(83)$ & $233(78)$ \\
\hline Smoker, $n$ (\%) & $104(21)$ & $56(19)$ \\
\hline Hypertension, $n(\%)$ & $285(59)$ & $178(60)$ \\
\hline Diabetes mellitus, $n(\%)$ & $61(13)$ & $34(11)$ \\
\hline Dyslipidemia, $n(\%)$ & $354(73)$ & $200(67)$ \\
\hline $\begin{array}{l}\text { Left ventricular } \\
\text { ejection fraction [\%] }\end{array}$ & $32 \pm 10 \pm 11$ \\
\hline $\begin{array}{l}\text { ACE inhibitors or } \\
\text { angiotensin receptor } \\
\text { blockers, } n \text { (\%) }\end{array}$ & $245(51)$ & $149(50)$ \\
\hline Beta-blockers, $n(\%)$ & $301(62)$ & $180(60)$ \\
\hline Statins, $n$ (\%) & $349(72)$ & $197(66)$ \\
\hline Digoxin, $n$ (\%) & $106(22)$ & $72(24)$ \\
\hline Amiodarone, $n(\%)$ & $114(24)$ & $56(19)$ \\
\hline Sotalol, $n$ (\%) & $23(5)$ & $839 \pm 1037$ \\
\hline Follow-up [days] & $965 \pm 961$ & \\
\hline
\end{tabular}

No significant differences were present between the 2 groups ACE - angiotensin-converting enzyme 
Table II. Incidence of appropriate cardioverterdefibrillator shocks and of mortality in patients with ischemic cardiomyopathy vs. nonischemic cardiomyopathy

\begin{tabular}{|lccc|}
\hline Variable & $\begin{array}{c}\text { Ischemic } \\
\text { cardiomyopathy } \\
(n=485)\end{array}$ & $\begin{array}{c}\text { Nonischemic } \\
\text { cardiomyopathy } \\
(n=299)\end{array}$ & $p$ value \\
\hline $\begin{array}{l}\text { Appropriate } \\
\text { ICD shocks, } \\
n(\%)\end{array}$ & $93(31)$ & NS \\
\hline $\begin{array}{l}\text { Mortality, } \\
n(\%)\end{array}$ & $162(33)$ & $70(23)$ & 0.002 \\
\hline
\end{tabular}

ICD - implantable cardioverter-defibrillator, NS - not significant

infarction, and 6 (9\%) died of a noncardiac cause. The only significant difference in cause of death between the 2 groups was fatal myocardial infarction ( $p=0.03$ by Fisher's exact test).

\section{Discussion}

ICDs have been shown to reduce all-cause mortality in patients with ischemic heart disease [1-5] and in patients with nonischemic cardiomyopathy $[5,6]$. At 30-month follow-up of 148 patients with ischemic heart disease and an ICD and of 60 patients with nonischemic heart disease and an ICD, ventricular tachycardia and ventricular fibrillation episodes per month were not significantly different between the 2 groups [7]. At 19-month follow-up of 105 patients with ischemic cardiomyopathy and of 48 patients with nonischemic cardiomyopathy and nonsustained ventricular tachycardia, appropriate ICD shocks occurred in $50 \%$ of patients with nonischemic cardiomyopathy versus $36 \%$ of patients with ischemic cardiomyopathy ( $p$ not significant). At 33-month follow-up of 485 patients with ischemic cardiomyopathy and of 299 patients with nonischemic cardiomyopathy in the present study, the incidence of appropriate ICD shocks was 37\% in patients with ischemic cardiomyopathy versus $31 \%$ in patients with nonischemic cardiomyopathy (p not significant). Unlike the other 2 studies [7, 8], there was no significant difference in baseline characteristics between patients with ischemic versus nonischemic cardiomyopathy in the present study. In other studies, appropriate ICD shocks occurred at 33-month follow-up in 329 of 1,038 patients (32\%) [11], at 70-month follow-up in 421 of 1,382 patients (31\%) [12], at 17-month follow-up in 169 of 719 patients (24\%) in the Multicenter Automatic Defibrillator Implantation Trial II [13], at 29-month follow-up in 33 of 229 patients (14\%) with nonischemic cardiomyopathy in the Defibrillators in Non-Ischemic Cardiomyopathy Treatment Evaluation Trial [14], and at 31-month follow-up in 52 of 140 patients (37\%) with nonischemic cardiomyopathy [15]. Since the incidence of appropriate ICD shocks in the present study and in those previously reported [11-15] varied from $14 \%$ to $37 \%$, this should be considered a limitation of the current guidelines for ICD implantation. Patients in our study with appropriate ICD shocks who died died of congestive heart failure or fatal myocardial infarction instead of sudden cardiac death.

In the present study, the low use of angiotensinconverting enzyme inhibitors or angiotensin receptor blockers ( $51 \%$ in patients with ischemic cardiomyopathy and $50 \%$ in patients with nonischemic cardiomyopathy) was due to low blood pressure or renal insufficiency in patients. Statins were administered to 197 of 299 patients (66\%) with nonischemic cardiomyopathy because these 197 patients had dyslipidemia.

Confounding factors for appropriate ICD shocks and for all-cause mortality are listed in Table I. Statistical analysis showed no significance difference in any of the confounding variables between patients with ischemic cardiomyopathy versus nonischemic cardiomyopathy.

In the study by Ermis et al. [7], there were 250 patients with ICDs. Mortality was $19 \%$ in patients with ischemic cardiomyopathy versus $11 \%$ in patients with nonischemic cardiomyopathy ( $p$ value not stated). The number of patients with nonischemic cardiomyopathy versus ischemic cardiomyopathy, the follow-up time for each group, and the baseline characteristics of each group for the 250 patients are not stated [7].

In the study by Evonich et al. [8], at 19-month follow-up, 12 of 105 patients (11\%) with ischemic cardiomyopathy and 2 of 48 patients with nonischemic cardiomyopathy (4\%) had died ( $p$ not significant). In the present study, at 33-month follow-up, 162 of 485 patients (33\%) with ischemic cardiomyopathy and 70 of 299 patients (23\%) with nonischemic cardiomyopathy had died ( $p=0.002$ ).

In conclusion, the present study and 2 smaller studies [7, 8] showed no significant difference in appropriate ICD shocks at follow-up between patients with ischemic cardiomyopathy and nonischemic cardiomyopathy. The present study showed a significantly higher mortality at follow-up in patients with ischemic cardiomyopathy versus nonischemic cardiomyopathy and no significant differences in baseline characteristics $(p=0.002)$. The small number of patients with nonischemic cardiomyopathy in the 2 other studies is a limitation for mortality data in these studies [7, 8]. Additional studies with large numbers of patients with ischemic cardiomyopathy and nonischemic cardiomyopathy with ICDs are needed to confirm our data. 


\section{Acknowledgment}

The results of the study were presented at the Annual Scientific Meeting of the European Society of Cardiology in Barcelona, Spain on August 30, 2009.

\section{References}

1. Moss AJ, Hall WJ, Cannom DS, et al. Improved survival with an implanted defibrillator in patients with coronary disease at high risk for ventricular arrhythmia. N Engl J Med 1996; 335: 1933-40.

2. The Antiarrhythmics versus Implantable Defibrillators (AVID) Investigators. A comparison of antiarrhythmicdrug therapy with implantable defibrillators in patients resuscitated from near-fatal ventricular arrhythmias. N Engl J Med 1997; 337: 1576-83.

3. Buxton AE, Lee KL, Fisher JD, et al. A randomized study of the prevention of sudden death in patients with coronary artery disease. N Engl J Med 1999; 341: 1882-90.

4. Moss AJ, Zareba W, Hall WJ, et al. Prophylactic implantation of a defibrillator in patients with myocardial infarction and reduced ejection fraction. N Engl J Med 2002; 346: 877-83.

5. Bardy GH, Lee KL, Mark DB, et al. Amiodarone or an implantable cardioverter-defibrillator for congestive heart failure. N Engl J Med 2005; 352: 225-37.

6. Kadish A, Dyer A, Daubert JP, et al. Prophylactic defibrillator implantation in patients with nonischemic dilated cardiomyopathy. N Engl J Med 2004; 350: 2151-2158.

7. Ermis C, Zhu AX, Vanheel L, et al. Comparison of ventricular arrhythmia frequency in patients with ischemic cardiomyopathy versus nonischemic cardiomyopathy treated with implantable cardioverter defibrillators. Am J Cardiol 2005; 96: 233-8.

8. Evonich RF, Maheshwari A, Gardiner JC, et al. Implantable cardioverter defibrillator therapy in patients with ischemic or non-ischemic cardiomyopathy and nonsustained ventricular tachycardia. J Interv Card Electrophysiol 2004; 11: 59-65.

9. Jessup M, Abraham WT, Casey DE, et al. 2009 focused update: ACCF/AHA guidelines for the diagnosis and management of heart failure in adults. A Report of the American College of Cardiology Foundation/American Heart Association Task Force on Practice Guidelines. Developed in collaboration with the International Society for Heart and Lung Transplantation. J Am Coll Cardiol 2009; 53: 1343-82.

10. Kannam H, Aronow WS, Chilappa K. Association of the QRS duration on the resting electrocardiogram with the severity of coronary artery disease in 2,196 patients undergoing coronary angiography for suspected coronary artery disease. Arch Med Sci 2009; 5: 163-5.

11. Kruger A, Aronow WS, Lai HM, et al. Prevalence of appropriate cardioverter-defibrillator shocks in 1038 consecutive patients with implantable cardioverterdefibrillators. Am J Therap 2009; 16: 323-5.

12. Tandri H, Griffith LS, Tang T, et al. Clinical course and longterm follow-up of patients receiving implantable cardioverter-defibrillators. Heart Rhythm 2006; 3: 762-8.

13. Singh JP, Hall WJ, McNitt S, et al. Factors influencing appropriate firing of the implanted defibrillator for ventricular tachycardia /fibrillation. Findings from the
Multicenter Automatic Defibrillator Implantation Trial II (MADIT-II). J Am Coll Cardiol 2005; 46: 1712-20.

14. Ellenbogen KA, Levine JH, Berger RD, et al. Defibrillators in Non-Ischemic Cardiomyopathy Treatment Evaluation (DEFINITE) Investigators. Are implantable cardioverter defibrillator shocks a surrogate for sudden cardiac death in patients with nonischemic cardiomyopathy? Circulation 2006; 113: 776-82.

15. Chen HA, Hsia HH, Vagelos R, et al. The effect of gender on mortality or appropriate shock in patients with nonischemic cardiomyopathy who have implantable cardioverter-defibrillators. Pacing Clin Electrophysiol 2007; 30: 390-4. 